Chapter 9

\title{
Occupational Therapy in Autism
}

\author{
Gonca Bumin, Meral Huri, Sinem Salar and \\ Hulya Kayihan
}

Additional information is available at the end of the chapter

http://dx.doi.org/10.5772/59168

\section{Introduction}

Autism, a developmental disability, is defined by behavioural characteristics. Primary features of autism are described as problems in language skills, plays and social interaction [1]. It is considered a spectrum disorder, as the abilities of children with autism may very greatly from one child to another [2]. Symptoms begin during early childhood and distinctive incompetence and limited, repetitive behaviours are seen in socio-communicative field. In addition to these primary features, individuals with autism generally have sensory processing and sensory integration dysfunction, which affect adaptive behaviour and participating daily activities. Many children with autism are unable to register many of the sensations from their environment. They cannot integrate those sensations to form a clear perception of space. Atypical sensory registration and orientation can interfere with the processes of inhibition and facilitation in sensory systems. Some self-stimulatory behaviour is the expression of a sensory need in children with autism. Assessing sensory integrative functioning in children with autism is critical for planning and implementing effective intervention in occupational therapy [3-5]. As far as motor functions are concerned, motor impairments have been reported in children with autism. The studies shown that problems are observed in coordination, posture and balance control, locomotion and motor preparation in individuals with autism [6-10].

Due to sensory integration dysfunction, individuals with autism have difficulty fulfilling the roles they are expected to accomplish in their life and they can display behaviours that can hinder their participation in daily life. The primary aim of occupational therapy practices is to ensure that the individuals with autism participate in communal life through minimizing the difficulties in the daily activities they experience at home, school or in communal life and maximizing their independency. Occupational therapists believe that the individual with autism's community participation can be increased through their participation in 
meaningful and purposeful activities they have in their daily roles and aims to achieve. They also make use of client-centred and holistic therapeutic interventions both in analysing and evaluating the problems which individuals with autism face and in their treatment and support system.

Occupational therapy interventions, which are designed according to standardized assessment tests, questionnaires, skilled observations, provide considerable advantage in dealing with the problems individuals with autism and their families face in daily life.

This chapter will give information on standardized assessment tests and practices applied in occupational therapy interventions such as sensory integration therapy, auditory integration training, activities of daily living training, play therapy, social skills training, cognitive behavioural therapy, school based intervention, recreational activities and sports and vocational rehabilitation.

\section{Sensory integration therapy}

Current estimates indicate that accompanying sensory processing problems are reported in more than $80 \%$ children with autism. Hyper or hypo reactivity to sensory inputs is now a diagnostic criterion for Autism Spectrum Disorders in the Diagnostic and Statistical Manual of Mental Disorders-Fifth Edition [11, 12]. A. Jean Ayres, an occupational therapist, developed the sensory Integration theory [13]. Theory is based on neuroscience, developmental psychology, occupational therapy and education sciences. Sensory integration therapy is a common method used in paediatric occupational therapy. Results of a survey made on occupational therapists working with children with autism report that $99 \%$ of therapists stated that they were referring to sensory integration therapy [14]. According to this theory; 1.sensorymotor development is important for learning 2. Individual's interaction with environments shapes brain development 3 . Neurological system has plasticity capability. 4 . Meaningful sensorymotor activity is a strong mediator of plasticity [15]. Sensory integration is a process of organizing sensory information in brain in order to create an adaptive response. The aim of sensory integration therapy is to provide controlled and meaningful sensory experiences so that the child can spontaneously and appropriately form responses that require integration of those sensations [16].

\subsection{The importance of sensation}

According to the theoretical basis of sensory integration vestibular, proprioceptive, tactile, auditory and visual systems as well as olfaction (sense of smell) and gestation (sense of taste) have a significant importance. The tactile/proprioceptive and vestibular/proprioceptive systems interact routinely with the auditory and visual systems to supply the multimodal sensory information needed to make a meaningful motor response. It's reported that sensory integration is a dynamic process that sustains during development and sensory information can be organized as a result of interaction with environment [17]. 


\subsubsection{Tactile system}

Skin has numerous receptors that perceive touching, pressure, texture, heat, pain and movement. A signal is transmitted to the related parts of the brain when tactile receptors are stimulated with touch, heat or vibration. Tactile system is a sensory system that affects behaviour both physically and mentally. Sense of touch is quite important for neural organization and praxis development $[16,18]$.

\subsubsection{Vestibular system}

Vestibular receptors related with balance and gravity, and located in inner ear consist of semicircular canals, utricle and saccule. Semi-circular canals are responsible for detection of angular, fast, short bursts of motion, and result in phasic limb movements and momentary head righting. Vestibular system is a system that affects balance, eye movements, posture, muscle tonus and attention $[16,19]$.

\subsubsection{Proprioseptive system}

This system is related with position and movement. Pushing and pulling activities related with muscles and joints are activities that provide maximum stimulation for this system. Proprioceptive system provides information on postural and oculomotor control, position in space and balance together with vestibular and visual system. In terms of the problems reported in vestibular and proprioceptive system, difficulties in good body scheme and laterality development, poor balance, poor postural control and difficulties in coordinated movements are observed in children with autism [2, 16-18].

Children who are hypo responsive against proprioceptive stimulation have weak proprioceptive discrimination and awareness and fail to use proprioceptive input correctly. Therefore they tend to break their toys easily and have low postural tonus. Bites, pushes, hits, scratches, bumps, hurls, hangs and aggressive behaviours as well as self stimulatory and hyperactive behaviours such as banging head, biting hands are observed in children seeking for proprioceptive inputs [20].

\subsubsection{Auditory system}

The sound information from each ear goes to auditory cortex of opposite hemisphere. The relation between the auditory system and valgus nerve is important in sensory modulation [16].

\subsubsection{Visual system}

The light received stimulates retina in order to send sensory input to the processing centre in the brain. Integration of visual inputs with different senses provides our awareness about our environments. Visual and vestibular systems work together for perceptual motor integration and visual perception $[16,18]$. 


\subsubsection{Gustatory sense}

Different senses of tastes ensure that we like the food we eat and distinguish those that may be harmful [16].

\subsubsection{Olfactory sense}

Smell is directly processed via limbic system and creates memories and associations that influence some of our choices and preferences [16].

It's reported that sensory processing problems observed in individuals with autism are associated with behavioural and/or functional performance problems and specifically stereotypical or repetitive are associated with self-calm or sensory seeking [21]. The studies show that repetitive behaviours, behaviours such as climbing, turning and twirling may indicate existence of sensory processing behaviours [12].

Sensory registration, modulation, discrimination and praxis defined as motor behaviour planning capability are performance components, which are important for sensory integration. Sensory registration is receiving different stimulus from body or environment [17]. Sensory registration process is important for the individual to perform effective function by paying attention. Children with autism who have sensory registration problems fail in creating appropriate adaptive responses against pain, touch, movement, taste, smell, light and sound [22]. Sensory modulation is defined as "capacity to regulate and organize the degree, intensity, and the nature of responses to sensory input in a graded and adaptive manner" [17]. Sensory discrimination is important for development of motor functions, postural tonus and postural adjustment. Different sensory modulation problems such as hyporesponsivity, hyperresponsivity, sensory avoiding or sensory seeking are reported in children with autism. Hypersensitivity is the most common auditory and tactile defensiveness. High pain tolerance is the most significant indicator of hypo responsiveness in children with autism [2].

Difficulty in starting and sustaining a social interaction and relation, delays in speaking or communication disorders such as echolalia, repetitive stereotypical plays, visually focusing on any object, cognitive deficits and confusions in impacts and results of behaviours are common sensory integrative - related behaviours in children with autism spectrum disorder. Poor sensory processing affects the child with autism in successful involvement in daily life activities such as playing and participating in social activities with peers, tooth brushing, eating, self care etc. [23].

\subsection{Sensory integration assessment and intervention}

"The Occupational Therapy Practice Framework: Domain and Process (AOTA, 2002)" which is a comprehensive guideline of assessment and intervention is used in the assessment of individuals with autism and in occupational therapy interventions. Accordingly, occupational profile should be initially defined, occupational performance should be assessed, intervention plan should be designed, objectives and goals should be identified and documented, intervention should be implemented and results of intervention should be assessed and documented [24]. 


\subsubsection{Assessment}

It is important to identify sensory responsiveness (over, under or labile) and sensory preferences (likes and dislikes) praxis and sensory processing problems that affect involvement in daily life activities in the assessment of sensory integration in children with autism [25].

Numerous tests like given below are used for assessment of sensory integration in occupational therapy.

Sensory Integration and Praxis Test (SIPT): It is developed to identify sensory integration problems. Test is standardized for use in children $4-8: 11$ years of age. SIPT assesses sensory and neurological process, which leads to behavioural, learning, language and praxis problems. It consists of 17 subtests, which assess tactile, vestibular proprioceptive processing; form and space perception, visual-motor coordination, praxis, bilateral integration and sequencing, and it takes nearly 90 minutes to complete the test [26].

Southern California Sensory Integration Test (SCSIT): It is developed by Ayres for use in physically and mentally normal children with specific learning disorder. It is standardized for children 4-8:11 years of age. It takes nearly 75-90 minutes to complete the test [27].

Southern California Postrotary Nystagmus Test (SCPNT): This test developed by Ayres to evaluate of nystagmus to field of occupational therapy. This test measures the amplitude of the eye's side to side excursion and the total duration in seconds of ocular movements following rotations [28].

Sensory Profile: The Sensory Profile is a caregiver questionnaire, which measures children's responses to sensory events in everyday life for children 3-10 years of age. 5-point likert scale (nearly never, seldom, occasionally, frequently, almost always) is used for assessment [29].

Evaluation of sensory processing:This questionnaire is intended to identify behaviors thought to be indicative of sensory processing problems [30].

Tests such as Developmental Test of Visual Motor Integration [31], Motor Free Visual Perception Test [32], Test of Visual Perceptual Skills (Non motor) [33] are used for the assessment of visual perceptual skills.

Besides standardized assessments, many occupational therapists refer to clinical observations for assessment of sensory and praxis functions. Clinical observation of postural control, behaviour organization and vestibular functions offer significant information in addition to sensory tests. It's important to observe playing skills, social interaction and other relevant behaviours of the child in child's natural settings [23]. Clinical Observations of Motor and Postural Skills is a screen tool for motor deficits and assessment of cerebellar function, postural control and motor coordination [34]. It's reported that Goal Attainment Scale (GAS) can used in measurement of results in sensory integration studies [35].

\subsubsection{Intervention}

It's reported that sensory integration therapy should be individually implemented with the consideration of the "inner drive" of the child, based on the sensory experience, challenge and 
interest and in a structured environments with active participation of the child [16, 22]. More effective feed-forward mechanism required for optimum adaptive response are created with child-directed actions. In responding children with autism, it is important to use controlled and meaningful sensory stimulus to create organized behaviour and to make environmental adaptations when needed. Due to the problems in body awareness, a child with autism fails in receiving sufficient tactile, proprioceptive and vestibular inputs from his/her body. Therefore, environmental arrangements should be adjusted according to motor planning and body awareness required for praxis. It's important to refer to sensory experiences that motivate and please the child with complex motor planning, social interaction and language skills. Therapist should integrate activities that contain sensory experiences required by the child into daily routine in cooperation with the family, caregivers and teachers [23]. Validity of the results in sensory integration studies are reported to be influenced by different practices in the intervention process and it's further reported that "Ayres Sensory Integration Fidelity Measure" which is a reliable and applicable verification measure for studies on sensory integration disorders should be used [36, 37].

Fidelity measure consists of 10 essential elements is used in clinic based sensory integration treatment. These essential elements are as follows: a) ensuring safety b) presenting a range of sensory opportunities (specifically tactile, proprioceptive, and vestibular) c) Using activity and arranging the environment to help the child maintain self regulation and alertness d) challenging postural, ocular, oral, or bilateral motor control e) is challenging praxis and organisation of behaviour $\mathrm{f}$ ) collaborating with the child on activity choices $\mathrm{g}$ ) tailoring activities to present the "just -right challenge", h) ensuring that activities are successful, i) supporting the child's intrinsic motivation to play, and j) establishing a therapeutic alliance with the child [37].

\section{Activities for proprioceptive system}

Proprioception is defined as a cornerstone in sensory integration therapy. Muscle movements against resistance or gravity, traction, compression, movements related with muscles and joints provide proprioceptive stimulus and are used to improve motor coordination, to increase body awareness and to help arousal level modulation [2, 20].Practices like jumping on trampoline, climbing a mountain of bolster and crash onto mats, jumping games, roller skating, bicycle riding, throwing and catching a heavy ball, wheelbarrow walking, pulling and pushing activities, carrying or moving heavy objects, imitating animal walks that require heavy work (crab, bear), swinging from trapeze bar, wearing a weighted west, weighted blanket, wearing ankle or wrist weights in activities stimulates proprioceptive system [23, 38]. (Figure 1)

\section{Activities for tactile system}

Activities like playing with dough or clay type materials, drawing on mirror with shaving cream, finger painting, drawing shapes with fingers in sand, foam etc, massage, vibrating toys, using different textures for playing and bathing, playing hide and seek games in dried beans or rice, asking the child to define shapes drawn on this/her back with fingers, finding objects from a bag full of rice or beans etc. can be used to improve tactile awareness [23, 38]. 


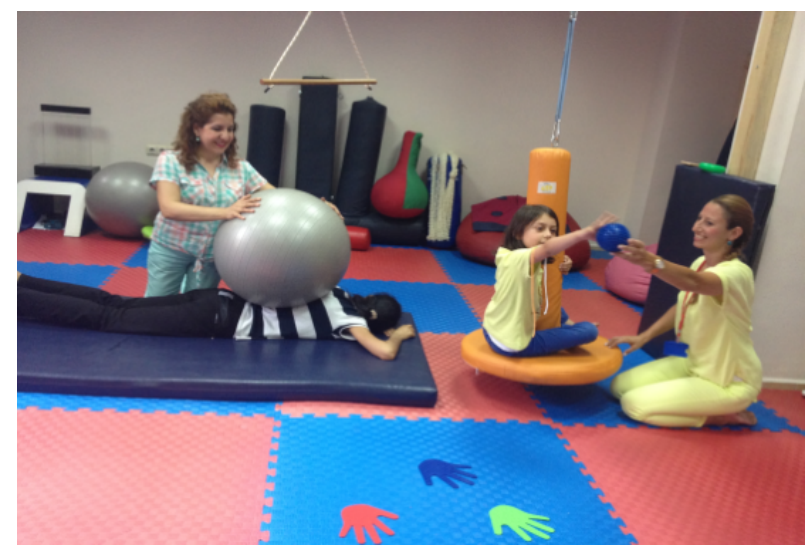

Figure 1. Activity examples for proprioseptive and vestibular system stimulation

\section{Activities for auditory system}

The child may be asked to listen his/her favourite soft music on headphones in order to reduce auditory sensitivity [23].

\section{Activities for vestibular system}

Activities such as linear swinging on a swing or ball on facedown position, throwing and catching objects while swinging, sliding down a slide, climbing, using scooter board or skateboard, jumping games, rolling activities, toys like rocking horse can be used to reduce sensitivity against vestibular senses. The child tolerates linear vestibular stimulus more than rotational stimulus $[23,38]$.

\section{Activities for ocular-motor control}

Toys and pens with lights, throwing balls at a target while swinging, games of ball throwing and catching, bubble blowing can be used to improve ocular-motor control $[23,38]$.

\section{Activities for postural control and motor skills}

Ball catching games can be played on the floor or on a ball or while sitting in different positions on a swing $[23,38]$.

\section{Activities for bilateral motor coordination and praxis}

Activities such as creating shapes by tearing papers with both hands, making shapes with play dough, cutting papers etc. with scissors, making necklace by placing beads through a string, closing/opening clothe fasteners, ball catching and throwing and clapping type hand games[23, 38].

\section{Activities for praxis and behaviour organization}

Therapeutic activities, which are for sensory processing and facilitate skills such as initiation, sequencing, bilateral coordination, timing and imitation can be used [5]. Activities of clapping 
and rhythm patterns hand games, building obstacle courses, activities that require whole body movements and timing such as kicking a rolled ball, hitting a ball with a bat, imitation of animal postures etc. can be used to improve motor planning [23, 38].

\subsection{Researches about sensory integration therapy}

Sensory integration therapy is a clinical based intervention that uses play activities and sensory integration principles to increase adaptive responses of children [12]. In a systematic review research by Benson and Koomar, 27 studies on the impact of sensory integration approach on children were reviewed. It's reported that sensory integration approaches are effective in terms of sensory-motor skills, motor planning, socialization, attention and behavioural regulation, skills related with reading, active participation in plays and personal goal attainment, however, the findings are limited due to small sample size, different practice dosages, therapy duration and result measurements not being appropriate [39].

Schaaf et al implemented sensory integration protocol for 10 weeks on a case with autism and consequently an increase was reported in sensory processing and home, school and family activities measured with Goal Attainment Scale [40]. Another study by Schaaf et al reviewed the safety, validity and applicability of sensory integration and occupational therapy in children with autism. 10 children with autism at 4-8 years of age were under therapy for 3 days a week for 6 weeks and an assessment was made with Ayres Sensory Integration Fidelity Measure. Sensory integration approaches in children with autism were reported to be a safe and applicable intervention [41]. Sensory integration therapy of 10 weeks for pre-schooler children with autism resulted with a decrease in non-engagement behaviours and an improvement in purposeful behaviours [42].

Pfeiffer et al reviewed the impact of fine motor activity with sensory integration therapy in 37 children between the ages of 6 and 12 with autism spectrum disorders in randomized controlled studies. Consequent to practice of 18 sessions, each for 45 minutes for six weeks, a significant improvement was reported in the sensory integration group. In sensory integration group, positive changes in sensory processing, motor skills and social functions and decrease in stereotypical and self-stimulating behaviours were reported [43]. A study by Smith et al reports that self-stimulating and self-injurious behaviours remain stable in children with pervasive developmental disorders as a result of sensory integration therapy [44]. Sensory integration and sensory based treatments resulted in increase in engagement in plays and social interaction, proper adaptive response, decrease in stereotypical and self-stimulating behaviours, decrease in sensitivity against touching and movement in hyper responsive children and decrease in sensory vulnerability. Sensory integration therapy improves skills of engagement in social interaction and modulating behaviours $[45,46]$.

Some studies report that sensory integration therapy does not have a positive impact due to small sample size, short therapy duration, no fidelity measure, study design and due to the fact that assessments are not blinded [47-51]. 
The last systematic review study by Smith et al. on sensory integration notes that evidence based studies where blinded evaluation, larger samples and randomised trial are used should be conducted [12].

\section{Auditory integration therapy}

Auditory processing problems are one of the sensory processing disorders commonly reported in children with autism. These disorders are classified either as auditory hypersensitivity or auditory underresponsivity $[3,52,53]$ and Rimland and Edelson reported that nearly $40 \%$ of 17.000 children with autism have sound sensitivity [54].

Auditory Integration Therapy is a technique developed by Dr Guy Berard, an otorhinolaryngologist in order to reduce abnormal sound sensitivity in autism spectrum disorders. In this method, electronically modulated music is listened by headphones for half an hour twice a day for 10 days. Audio metrical assessment is made before the therapy. Auditory integration training devices filters peak frequencies against which the individual has hypersensitivity. It aims to regulate behaviour by reducing hypersensitivity. The filtered music is modulated by a brief dampening of high and low frequencies for periods ranging from 250 milliseconds to 2 seconds [54-56].

445 individuals with autism who received auditory integration therapy were reported to have a decrease in problem behaviours and increased hearing acuity and the observed changes remained stable for nine months [57].

Changes in brain functions were measured before and after auditory integration therapy with positron emission tomography and an increase in occipital lobe activity and a decrease in hyper metabolism in frontal lobe were reported [58]. Auditory therapy according to Tomatis method is reported to create an increase in daily life skills, motor skills, socialization and communication skills in 6 cases. Furthermore, decrease in hyperactivity, atypical behaviours and increase in attention was reported in cases [59]. Brockett et al assessed impacts of auditory integration training on behavioural changes related with sensory modulation in children with autism. Following a 10-days training for two times a day, a decrease was reported in sensory behaviour problems of children [60]. In 72 cases with autism spectrum disorders, auditory integration therapy was reported to have a therapeutic impact on social awareness, social cognition and social communication as well as speech and communication [61]. Some studies report that there is not difference between auditory integration therapy and control group and that evidence based studies are required [62-64].

\section{Activities of daily living}

Activities of daily living (ADLs) are oriented toward taking care of one's own body and include bathing, dressing, eating, feeding, bowel and bladder management, functional mobility, 
personal device care, personal hygiene and grooming, sexual activity and toilet hygiene. These activities are "fundamental to living in a social world; they enable basic survival and wellbeing". Instrumental activities of daily living (IADLs) may require more complex interactions with one's environment; these activities support daily life within the client's home and community. IADLs include: communication management, home establishment and management, meal preparation and clean up, financial and health management and maintenance, community mobility, shopping, safety and emergency maintenance, care of others and pets, child rearing and religious observance. Children and young people learn to perform ADL and IADL activities with socially appropriate ways in order to engage in education in family and society, game playing, leisure, social participation and work occupations [65].

Individuals with autism generally have the risk of limited engagement in activities. Studies show that such individuals engage in less activities less frequently and have weaker daily life skills when compared with individuals with other developmental disorders or with typical development [66-70]. Most common areas reported by families are limited independence in dressing, rigid eating routines, interruption of eating time because of difficult behaviour, limited independence and discomfort in many hygiene tasks, obvious difficulty in toilet training, limited engagement in chores and continuous and intense supervision to provide safety [71]. Engagement of individuals with autism in daily living activities may be effected by core characteristics specific to autism as well as sensory processes. Studies show that $42-88$ $\%$ of individuals with autism experience sensory integration disorders [72-76]. Koenig and Rudney demonstrate in a review that children and adolescents who have sensory processing deficits have difficulties in completing their daily occupations, including ADLs and IADLs [77]. While the literature underlines the need to increase evidence-based studies, sensory integration deficits of individuals and sensory features of environment should not be ignored in assessments and interventions for activity engagements of individuals with autism.

\subsection{Assessment}

ADL and IADL assessments start with analysis of occupational performance. For this purpose, interviews, inventories, observation and various standardized tests can be used as an assessment method. In the initial stage, interview with family, child, teacher and other care givers is important in learning child's skills, habits, routines and roles, environmental features, goals and dreams [78]. If the family reports difficulties about some ADL or IADLs of child, therapist should observe the child in clinic or ideally at home if possible and in child's environment during the activity. Assessment should contain information on social, cultural and physical environment, which affect activity performance as much as motor, process and communication/ interaction skills of the child. Environmental factors such as division of labour division of family members for child's care, safety issues in physical environment and cultural habits and social routines of family may be registered. Task analysis is made to define activity demand, activity is divided into steps and reviewed, steps are listed and requirements are defined. The Functional Independence Measure for Children (WEFIM), Waisman Activities of Daily Living (W-ADL) Scale, The Paediatric Evaluation of Disability Inventory (PEDI), The Vineland Adaptive Behaviour Scales, The Assessment of Motor and Process Skills (AMPS), 
The Canadian Occupational Performance Measure (COPM) and Sensory Profile (SP) for sensory integration are some of the examples of standardized methods that can be used in the assessment of performance in daily living activities [29, 79-85].

\subsection{Intervention}

Occupational therapists may refer to different approaches to improve ADL and IADL performances in children, including 1) establishing and maintaining performance, 2) activity adaptations or compensatory methods [78].

\subsubsection{Establishing and maintaining performance}

At the initial stage of intervention, therapist uses an activity analysis to define which steps of activity process are problematic and defines behavioural and educative methods to be used [78].

Behavioural approaches has been used, often in combination with other approaches, to obtain a baseline of the child's behaviours and as a way of establishing clear goals. Behavioural methods like reinforcement and token systems are useful in attainment and sustainment of skills in individuals with autism. Furthermore, besides guiding learning, they may facilitate visual (showing), verbal (speaking or written information), tactile (guidance or using a part of body) or environmental (colour coded materials) cues. Cues are important to improve the quality of performance and to brief individual on what to do in the next step. As individuals with autism may experience difficulties in understanding natural cues and verbal communication, context or activity demands such as use of prompting can be modified [86].

One of the important training methods used in ADL training is chaining. Training of complex skills generally requires chaining steps of the task. Three chaining options are available for functional task training: a) Backward chaining in which the last step of the task is trained first, followed by the second to last step and the last step, and so on, progressing backward through the chain, b) Forward chaining in which the first step of the chain is trained first, followed by the first and second step, and so on, progressing forward through the chain c)Whole task method in which each step of the chain is trained on each presentation [87]. Another method is time-delay procedures. The time-delay cueing system typically involves two training stages: 1) A cue designed to elicit the next step in the chain is delivered so as to coincide with the stimulus (i.e., the completion of the previous step in the chain). 2) A defined interval is inserted between the occurrence of the stimulus and the response-eliciting cue [88]. These educational methods include strategies that occupational therapists can use in skill training. Repetition and development of habits and routines are required to sustain the skill after it is learned and to reduce environmental supports. Furthermore, generalization of skill in different environments should be emphasized [78].

\subsubsection{Activity adaptations or compensatory methods}

Compensatory strategies may include modification of task or task method, use of assistive technology or modification of environment. Therapists may also refer to the combination of these methods [78]: 


\section{- Adaptation of task methods}

"Grading" is a method commonly used by therapists. Grading is adaptation of task or parts of a task according to the capability of child. Activity is divided into subtasks with task analysis and task is modified depending on the difficulty or easiness level for the child [78].

\section{- Visual Strategies}

Individuals with autism can process visual information easier than auditory information [89]. Visually based interventions include visual (e.g., picture, written) schedules, visually organized tasks, written or pictorial scripts, rule reminder cards, and visual task analyses [90]. Such interventions are reported to be effective in individuals with autism [90,91]. These activities may be used for individuals with autism to learn activities of daily living skills, to foresee daily routine and to become independent from various environments [92].

\section{- Assistive Technology}

In literature, technologies like video modeling, video prompting, handheld devices, structured computer games and virtual reality environments are used for training purposes. Research incorporating technology has consistently demonstrated good effects to daily living skills for children with autism. Additionally, assistive technology requirement of occupational therapist, which technological tool is applicable and proper assessment of factors related with accessing technology such as economical status of family are important [92-95].

\section{- Sensory Strategies}

Creating sensory-friendly environments and implementing adaptive sensory strategies are important for effective ADL and IADL performance in children with sensory modulation problem. For instance, environment should be structured to be silent when an activity is performed with a child who has auditory-hyperresponsiveness responses. Use of earphone is recommended in environments that cannot be controlled. Another example is that preparation of a child with deep pressure and organized, rhythmical touches might be facilitating before starting a dressing activity with a tactile defensive child [23].

\section{Play in occupational therapy}

Besides being an activity that exists in every stage of life, play is the most proper way for a child to learn the world he/she lives in and to express emotions such as happiness, anxiety, and joy particularly during the first years of life. Bundy describes it as "play is a transaction between an individual and the environmental that is intrinsically motivated, internally controlled, and free of many of constraints of objective reality" [96].

Play is primer occupation of the child. Through play, children can gain developmental milestones, learn about occupational role, behaviours, and how to interact safely and appropriately within their environment. Children with autism display atypical and insufficient play skills at different levels. This atypical and insufficient play skill is generally reported as playing 
with a toy stereotypically (rotating, shaking, sequencing, putting one on top each other) which is not suitable for its function, lack of social skill, flexibility and creativity skill to continue the play. Developments in symbolic activity, play and social relation areas observed in children younger than three years of age are not generally reported in children with autism [97]. Rare interaction of children with autism with their peers limits their attainment of playing in solitary and group plays with their peers [98]. Since game playing requires developed motor planning and praxis skill, this may result in child's showing motor planning and praxis during play [96].

Occupational therapists are concerned with the occupation of play and the child developing as a lifelong player [99, 100]. Providing engagement with play in children with autism is one of the most important parameters of occupational therapy interventions [101]. The primary goal of occupational therapy interventions in children with autism is to ensure attainment of motor planning and praxis skills, which will improve child's concrete thinking and play setting skills [99-101].

Play is multidimensional phenomenon that includes entertainment, spontaneous problem solving skill and creativity and requires collaboration of different disciplines [101-103]. Engagement in play and sustainability of play continue as long as the self-motivation and creativity of the player continue. Active engagement of children with autism in play and sustainment of play with adaptive response is one of the most important objectives in occupational therapy interventions [96, 99-101].

Our senses (tactile, visual, auditory, olfactory, gustatory, proprioceptive and vestibular) help us to collect information from the environment we live in and provide that we give adaptive responses suitable for the environment and we generalize what we learn. Sensory information is effective in the establishment of body scheme, which is one of the most components of motor planning skill [13, 104-106]. Studies reported that integration of tactile, visual, proprioceptive and vestibular sensory inputs offer improvement of body-spatial awareness [106-108]. When children with autism fail to produce adaptive response suitable for their environment and have insufficient body scheme, such may lead to negative experiences in their occupational performances and may result in anxiety, frustration, anger and avoidance [109]. Therapeutic play used in occupational therapy intervention can lead the child into a motivating activity with inner drive that encourages active movement, self direction, interaction, sensory building blocks and help addressing occupational performance and occupational profile of the child with autism [106, 109]. A study assessing the effectiveness of play therapy in literature reports that DIR-Floor Time and similar developmental approaches have a positive impact on emotional functioning, communication, and daily living skills and moreover creates positive changes in parent-child interactions [110]. It's noted that play based occupational therapy improves motor and social skills in children with developmental delay [111]. Hebert reports in his study that therapeutic plays practiced for children with developmental delay in line with their occupational frameworks improve their non-verbal and verbal communication skills [112]. As noted by such evidence-based studies, well structured play which is commonly used in occupational therapy interventions has a positive impact on motor skill and planning, communication-interaction and social skills of children with autism. 


\subsection{Assessment}

Play is what children to do and they expend considerable social, cognitive and motor resources while playing, therefore play assessment may provide very meaningful insights about a child's interests, functional abilities and behaviours [113-115]. The selection of a play assessment will vary depending upon the developmental status of the child, the purpose of the assessment and the intervention plan. Test of Playfulness [114], Knox Preschool Play Scale [115], Play History [116-118] and Trans-disciplinary Play-based Assessment [119], My Child's Play [120, 121] tests are among the common standardized tests used to plan occupational therapy interventions for the improvement of play skills [117]. Furthermore, occupational therapists frequently refer to Observations of Factors Influencing Playfulness Form [121, 122] to plan their interventions.

\subsection{Intervention}

Occupational therapists frequently use sensory integration framework where sensory differences of individuals are taken into account in improving play skills of children with autism. Developmental approaches like Dr. Stanley Greenspan's "Floor Time" method which aims to turn the relation between children and their families into a play with mutual interaction that contains trust and pleasure and philosophy of "Follow the child's lead" [123-126]. Additionally, virtual reality studies are also included under play interventions [127]. During occupational therapy interventions, in addition to therapeutic use of play, occupational therapists play an effective role in the organization of play environment and parent education with the consideration of developmental level, challenges and strengths of child [128].

It's important for the occupational therapists to implement therapy programs designed according to sensory integration framework, under the leadership of child in structured environments for the improvement of motor skill, social-emotional well-being, cognitive process, praxis, attention, intimacy, interaction expression, use of feelings/ideas and logical thinking development of child with autism in play based occupational therapy interventions [129].

\section{Social skills training}

Social skills have a significant place in diagnosis of autism. Children with autism experience difficulties in using non-verbal behavioural social skills such as eye-to-eye gaze, facial expression, body postures and gestures to regulate social interaction; failure interaction with peers, problems on sharing enjoyment, interests or achievements with other people and problems in social-emotional reciprocity and may require support as of early ages. Individuals with autism have difficulty in understanding nuances and informal rules, which are spontaneously used during communication. Such social interaction problems may lead to indifference, teasing or bullying. Social interaction efforts of many individuals with autism result in negative experiences as the individual is over stimulated or confused and negatively effects the social engagement of individual. Studies report that negative reactions against individuals 
with autism from their environment are more challenging that their communication problems [130]. Difficulties in social skill behaviours observed in individuals with autism are defined with neuropsychological models such as the theory of mind [131, 132], executive functions $[133,134]$ and weak central coherence $[135,136]$.

Theory of mind is defined as the capacity of interpreting, deducing and explaining the underlying mental situations in other's behaviours. Preschool children are expected to have developed their theory of mind skills. Insufficient development of theory of mind are reported to lead to difficulties in interpreting emotional status from voice tone and facial expression and in social skills and negatively affects empathy skill of individual [131,132]. Theory of mind is used to describe the major deficits in social functionality and communication in autism [132].

Dynamic and complicated nature of information process in brain reveals definition of highlevel cognitive functions and concept of executive functions. This theory covers skills such as self-regulation of behaviour sequence, flexibility, response inhibition, planning and organization of behaviour. Executive functions where prefrontal cortex play a central role provides that an individual thinks about himself/ herself and defines what can happen in future and how they can be affected [133]. Executive functioning in autism is an approach studied fort he last 20 years. Studies on executive functioning and frontal lobe functions report that performances of children with autism in executive functions are lower than expected [133, 134]. Social skill deficits, namely executive function disorders or stereotypical behaviours, which are considered to be caused by their deficits, are observed in individuals on the spectrum and in their relatives [132-134].

According to weak central coherence model, information received from different sources cannot be integrated in autism [135]. Meaningful and consistent meronymy relation cannot be established from stimulus perceived due to information processing deficit. Weak central coherence can be associated with disadvantages experienced by individuals with autism in areas such as learning, social, language and cognitive skills etc. and it's reported to be the reason for behavioural deviations in these areas [136].

Different disciplines commonly agree that autism is centrally a social skill deficit and therefore this area should be the first area to be targeted in training [137]. In social skill studies for children with autism, attainment of basic skills such as eye contact, using expressions like hello, thank you which are the basics for social communication, answering questions like how are you, playing with peers and getting in line in plays etc. are targeted with priority [137, 138].

There are many advanced social skills that should be attained by a child with autism after the attainment of basic social skills. These social skills can be classified under four main groups; communication skills: self introduction, asking proper questions to meet someone new, starting a conversation, involving in a conversation, not deviating from topic of the conversation, listening in a proper position, not keeping the talk too long, changing the topic properly, using voice tone, facial expression and body posture according to the topic of the conversation [139-141].

Social interaction skills (friendship): These are the skills like touching properly, ringing, answering a call, helping a friend properly, asking for help, spending time together, acting at 
a proper distance depending on the type of relation, respecting ideas of others, not feeling uncomfortable with changes in rules etc. [140].

Social interaction skills (playing): These are the skills like engagement in play, sharing toys, playing games with rules, getting into a line during play, coping with winning and defeat [140, 141].

Emotion recognition and management skills: They include skills like awareness on emotions, consoling a sad person, anger control and expressing anger properly, accepting criticisms, coping with mocking, sharing happiness, coping with making mistakes, not feeling uncomfortable when trying new things. [140, 142].

Social skill training is not a routine part of occupational therapy interventions for individuals with autism. Occupational therapy interventions play an important role in designing intervention programs for the assessment and improvement of insufficient social initiations and responses against any occupational performance of the individual with autism at home, school or in society, and in enhancing social participation of individual [130].

In social skill studies with children with autism, skills are tried to be taught face to face or in groups or some skills are taught during playtime with parents or peers [140,141]. It's reported that a shift can be made from individual works to group works for the development of empathy skill [139]. These working principles are also taken into consideration in occupational therapy interventions [16].

Among the studies on improvement of social skills in children with autism, there are researchers who think that "theory of mind" is the problem [133, 142, 143], and studies, which refer to, structured training programs [140,144] or developmental approaches [145]. More than one technique is used in some studies. For instance various techniques like scenarios, social skill groups, self-control, class interventions, video modelling, social plays, peer training, peer mediation and circle of friends are used together [146-148]. There are also studies where a single technique is used like social stories [149], peer mediation etc. [150]. It's reported that social skill training of children with autism is more effective in communication with other children in a natural group setting [151].

In a study where 79 studies on children with autism under the age of 12 were reviewed, it was noted that modeling and reinforcement, approach, peer training, scenarios and social stories were used [138]. It's further noted that programs designed with techniques of approaches to learn social skills in groups or socially are more effective in children with autism [138, 152].

\subsection{Assessment}

In occupational therapy, social skills of individuals with autism are assessed with observational standardized tests and checklists [153]. Standardized tests helps assessment of social skills and daily living skills of an individual with autism. Vineland Adaptive Behaviour Scale [83] and Social Skills Rating System [154] can be given as an example of such tests.

Occupational therapists may make structured interviews with parents and caregivers in addition to the standardized tests, and make observations in the natural settings and structured 
play settings of the child. During the assessment, informal rating scales can be used in the observation of social skills of the child such as spontaneously engaging in communication, imitation, socially responding, eye contact, game playing, asking for help/ helping, adjusting voice tone, using body language, expressing emotions verbally and non-verbally, giving proper responses, distance with others during communication and interaction [16, 128, 155].

\subsection{Intervention}

Occupational therapy interventions for improvement of social skills in individuals with autism should be client-centred, with concrete narrations, supporting active engagement in cooperation with family and teachers in the natural settings of the individual and should consider emotional differences. Individuals with autism may experience significant difficulties in implementing the social rules despite having memory skills that facilitate repeating and memorizing these rules. Occupational therapists can give social skills training with creatively referring to the routine daily activities of the individual with autism during the sessions. A therapy program which starts with individual works of 30-90 minutes where necessary considerations and modifications are made over an activity related with the occupations of the individual with autism in his/her life and progresses with group works is considered as an ideal occupational therapy intervention. Adult-mediated or peer-mediated activities can be used in intervention. Teaching that the same response would not be proper in every social situation with the consideration of social hierarchy and group work principles during the intervention is an important detail of the intervention [16, 128, 155].

Social Stories and Social Autopsies, Social Skills Lessons and Activities, Jump Starters, Social Skills Activities for Special Needs, and Walker Social Skills Curriculum: The Accepts Programme, Do-Watch-Listen-Say" Framework, Video Modeling methods are frequently used in occupational therapy interventions [156-158].

Occupational therapy interventions designed to improve occupational performance in line with the basic principles given above may help in the development of social skills in individuals with autism and can increase their social engagement levels.

\section{Cognitive behavioral therapy}

The cognitive behavioural approach assumes that a person's cognitive function and beliefs influence their behaviour, and that by helping a person dispute their irrational thoughts, they will be empowered to change their behaviour [159].

Each person's beliefs are developed through his or her own life experiences. These experiences can be lived as well as watched (observational learning, vicarious reinforcement etc.). Individuals with autism can have problems on learning from society, and vicarious reinforcement is key aspects of Bandura's social learning theory [160]. Cognitive behavioural therapy is used primarily to help individuals with autism to regulate their emotions, develop impulse control, and improve their behaviour as a result. In addition, some individuals with autism struggle 
with fears and anxiety, or may become depressed. Cognitive behavioural therapy has been shown to be helpful for reducing anxious and depressed feelings and behaviour by making changes in thoughts and perceptions of situations through a change in cognition. The key ingredient of cognitive behaviour therapy based occupational therapy, which distinguishes it from regular behaviour therapy, is working on change in cognition or how thinking is processed [160, 161]. Occupational therapists seek to reduce challenging behaviours, such as interruptions, obsessions, meltdowns or angry outbursts, while also teaching individuals how to become familiar with and manage certain feelings that may arise during activities of daily living. Cognitive behavioural therapy can be individualized which matches client-centred approach of occupational therapy, and as a result, is very effective at improving very specific behaviours and challenges in each individual with autism. Stabilizing emotions and improving behaviour allows individuals with autism to prepare for and respond more appropriately in specific situations [159-161].

Occupational therapists working with individuals with autism refer to at least one behavioural approach, generally the frameworks of model of human occupation and biopsychosocial model in their therapy interventions [159, 162, 163]. Occupational therapists support the cognitive behavioural therapies implemented in line with these models with making changes in individual-environment-activity areas [159, 162-164]. Following cognitive behavioural therapy, occupational therapist assists an individual with autism to identify and change their irrational thoughts, then take this learning and use it in real life opportunities [159, 162, 163].

Although studies on mental health are frequently observed when cognitive behavioural therapy based occupational therapy interventions are reviewed, visually based interventions such as video modeling where behavioural changes are targeted with various activities have been demonstrated to be effective with children with autism. This approach has wide utility, is appropriate for a range of ages and abilities of children with autism. There are video modeling studies such as Video Self (modeling Tape the child and play back to give feedback), Video Instruction (tape another student doing the behaviour) and Video Feed-Forward Tape. These studies show the child the complete behaviour and promotes independent functioning, and can be used to address numerous learner objectives of occupational therapy, including behavioural, self-help, communication, and social objectives [164-166].

\subsection{Assessment}

Occupational therapists generally work in line with model of human occupation and biopsychosocial model in the interventions of cognitive behavioural-based therapies in individuals with autism [159, 162, 163]. Besides the assessments of occupational therapy frame of reference, assessments such as 5 Point Scale, Power Cards, Bibliotherapy, Video Modeling, SituationsOptions-Consequences-Choices-Strategies-Simulation, Social Autopsies, Comic Strip Conversation, Social Stories and Hidden Curriculum are used [156, 167-173]. Furthermore, a review also found that ILAUGH Model had already been researched and demonstrated to be a relevant learning hurdle for individual with autism [174]. 


\subsection{Intervention}

There are some programs designed for children and adolescents to teach awareness of energy levels and self-regulation. Alert Programme "How Does Your Engine Run?" is one of them and it teaches awareness of energy levels and how to bring the energy level back to the centre and it focuses on self-regulation skills according to sensory integration theory [175].

Occupational therapists also aim to improve the skills of exploring feelings in their activities with children with autism. For this purpose, programs of Thinking about You Thinking about Me [176], Think Social like ILAUGH [174,177] are frequently used to improve communication skills and problem solving skills of individuals with autism. Additionally, books used to improve social thinking skills of children with autism are also frequently used in activities of occupational therapists. Again, "Superfleks Series" [178] by Winner is commonly used in occupational therapies planned specifically for behavioural changes in children with high functioning autism.

Anxiety can be debilitating for a child with autism. Learning about emotions helps children recognize connections between thinking and feeling, and helps them identify the physiological effects of anxiety on the body (sweating, increased heart rate, crying, etc.). Learning and teaching to explore feelings can help the child with autism to identify situations that make them anxious and learn how to perceive the situation differently [179]. Therefore, occupational therapists frequently refer to self-management training in coping with anxiety and stress in their studies with children with autism. Effectiveness of intervention in individuals with autism who receive cognitive behavioural therapy based occupational therapy is assessed with Goal Attainment Scale (GAS) [35].

\section{School based occupational therapy}

Occupational therapy in school is quite different from clinic based occupational therapy. School-based occupational therapists focus on learning, developing skills which increase the student's independence in the school environment, and also educating the school personnel about the different considerations required for students to eliminate the barriers from participation [180-183].

Everything the occupational therapist does with student in school must be related to develop educational skills of the student with autism. The occupational therapist evaluates, assesses and accommodates functional abilities of the student with autism in school classrooms, hallways and other related education areas. The occupational therapist works with teachers to help student's acquire functional abilities necessary to access and use educational materials and be independent in the school [183]. Occupational therapists work with the students with autism on adapting or modifying school equipment/materials to help them function better in classrooms, the lunchroom, or restrooms. Other assistance includes helping students with autism to be sensory stable and participate in activities outside of the school through mobility on field trips, sports events, on playgrounds and within the community. Students with autism 
face a demanding environment at school [183-185]. Presentation methods for educational materials must be modified to meet the challenges of students with autism, such as their ability to communicate, view and manipulate educational materials, and move about the school. Occupational therapists work closely with teachers to promote the highest level of function possible for a child with autism pursuing educational goals like fine and gross motor skills and attention skills [185-188].

\subsection{Assessment}

Occupational therapists use screening, assessment, and clinical observation tools and strategies to analyse why child with autism is having functional and sensory difficulties in educational settings not to establish interventions in school settings. During their interventions occupational therapists use some of the standardized tests like Sensory Profile [189, 190], Bayley Scales of Infant Development-II [191], Peabody Developmental Motor Scale [192], Bruininks-Oseretsky Test of Motor Proficiency [193], and Pediatric Evaluation of Disability Inventory Test [82] in school setting [194].

If the standardized tests are not appropriate, occupational therapist can give descriptive reports without using standardized scales. It is important to compare the child's performance with the previous scores than the normative sample. Occupational therapists can use play based performance profiles like Hawaii Early Learning Profile or Transdisciplinary Play-Based Assessment [194]. Additionally ecological/environment inventories should be used to evaluate child with autism within a variety of educational environments (classroom, garden, sports area etc.), curricular expectations; tools/instruments to help gather relevant information; whether the team needs expansion to obtain needed information [195, 196]. And also to determine and work with the educational team to determine functional strengths and challenges and providing information to design instructional programs of the student with autism. Occupational therapist should try to become familiar with the individual education plan [194-196].

\subsection{Intervention}

Occupational therapists use direct or indirect services for students with autism in school settings. Occupational therapy interventions purposes are to help students with autism to gain independence in daily living activities, feeding and oral functions, play skills, task organization and completion, written communication skills, hand function, sensory integration (processing), visual perception, campus/school mobility, participating on a regular and timely basis, using tools and supplies, participating in activities throughout school settings. Also when skill and strength cannot be developed or improved, occupational therapy offers creative modifications and adaptations for carrying out development-appropriate activities [195, 196].

In school practice, occupational therapists work with students, teachers, families, classes, schools, and school districts. Occupational therapists are experts at identifying ways to engage students with autism in educational activities and supporting them to develop competence in their roles as students. 


\section{Recreation and sports}

Recreation, a participation domain of the International Classification of Functioning Disability and Health (ICF), includes involvement in formal and informal activities such as play, sports, going to the theatre, crafts and tourism [197]. Leisure in occupational therapy is described as one of the occupational areas that cover recreational activities. Leisure is defined as "'A nonobligatory activity that is intrinsically motivating and engaged in during discretionary time, that is, time not committed to obligatory obligations such as work, self-care, or sleep'" [99]. Engagement in challenging and intrinsically motivating recreation and leisure activities is considered as an important part of development of children and young people [198]. These activities are reported to have positive impacts on physical and mental health, reduce behavioural and emotional disorders, facilitate becoming friends, widen interest areas of child and increase life satisfaction of family [199-202].

Besides being pleasant, recreational activities improve the life quality of individuals with autism, develop their social communication and acceptance, reduce inappropriate behaviours, improve fine and gross motor skills and helps in attainment of social skills [203]. Findings of studies on participation of children with autistic disorders in physical activities and sports activities show that sports and physical activities may create opportunities for social interaction, reduce repetitive movements and contribute in development of motor performance and physical suitability as well as self management skills [204-207].

Studies show that children with autism have more limited participation in recreational activities when compared with their peers with typical development or those in other disability groups [208-211]. Core impairments of autism spectrum disorders (i.e., communication impairments, social deficits, and abnormal restrictive, repetitive and stereotyped behaviours) and other features related with disorder (e.g. motor skills differences and maladaptive behaviour) affect recreational participation [212]. Another significant factor is sensory integration problems experiences by individuals with autism. It's reported that children with autism and sensory difficulties participate in recreational activities less and prefer more informal (not structured) and home activities [213]. Besides all these individual features, the impact of family and environmental factors are also described. The interplay is noted among the child's impairments, the family's style, preferences, and demands, as well as environmental or community-based limitations in restricting a given child's ability to participate in an array of recreational activities [199]. Studies show that participation of families in recreational activities positively affect child's participation [214]. Furthermore, it's observed that number of accessible services in society is parallel to participation in these activities [199]. Another factor is acceptance perceived from family, friends and neighbours. Families of children with developmental delay and behavioural problems may discontinues activities outside home as a response to negative reactions of people against the noise and temper tantrums of child [215]. As a conclusion, holistic perspective is important.

Individuals with autism are in need of programs structured and organized with proper support to reveal their recreational interests and to improve their leisure skills [203]. Therefore interdisciplinary teamwork is an important issue. Considering multifaceted factors that affect 
participation in recreational activities, strong cooperation of families and professionals are required in the planning and implementation of intervention [208]. Occupational therapists are important both with their expertise in occupational participation and their knowledge on sensory integration interventions for participation of individuals with autism in recreational activities. Occupational therapists point out exploration and participation in leisure activities, which are one of the occupational areas. Leisure exploration refers to identifying interests, skills, opportunities, and appropriate leisure activities. Leisure participation is planning and participating in appropriate leisure activities; maintaining a balance of leisure activities with other areas of occupation; and obtaining, using, and maintaining equipment and supplies as appropriate [65].

\subsection{Assessment}

Occupational therapy assessment with an occupation-based, family-centred and top-down approach starts with an interview with the family and self-report. Family's perspective on interests and skills of child, life style, economical status, their access to social and community resources should be recorded. Ideally, leisure assessments should be made in the natural settings of the child whenever possible. Interview and observation made in this setting are important to assess physical, social, cultural, attitudinal or organizational environment factors which affect leisure participation of the child and to evaluate child's performance skills. It is important for the therapist to observe motor, process and social interaction skills and attitudes of the child against others during activities with peers [185].

Paediatric Activity Cart Shorting (PACS), Children's Assessment of Participation and Enjoyment (CAPE), Canadian Occupational Performance Measure (COPM) are some of the examples of standardized methods that can be used in the assessment of recreational interests and skills of the child $[85,216,217]$. It is important to assess the sensory integration skills of the child and impact of these skills on activities, to define strategies to meet the needs of the child and to create sensory friendly settings. Therefore Sensory Profile (SP) is a standardized scale used in defining sensory difficulties of child [29].

\subsection{Intervention}

Occupational therapists give trainings to families, friends and teachers on how to facilitate participation of individual besides teaching the most needed skills for participation of children in selected leisure activity. Additionally they give training on use of adaptive equipment required for activities and make environmental modifications.Participation of children with deficits in activities together with their peers without deficits is important for both groups. Some of the study results show that peer support programs are useful for both groups. Structuring recreational activities where children with autism can be together with children with typical development can be an effective for proper modeling and social integration of children with autism and for the positive attitude changes in others [218, 219].

One of the most important highlight of recreation and leisure activities is that they are "intrinsically motivated". Neurobiological studies show that limbic system which orchestrates 
motivation and drive in brain is not adequately developed in individuals with autism. According to sensory integration theory by Ayres, purposeful sensory-based activities may increase natural inner drive. Therefore, carefully selected sensory-based activities may help finding activity meaningful and purposeful and sustaining participation [220, 221].

Virtual Reality (VR) technology is an important tool to widen leisure activity spectrum of intellectual and developmental disability population. Easy changeability of virtual environments, adaptation and scaling of difficulty of task according to the skills of the individual can be considered as advantages of VR [222]. Furthermore, it increases motivation and leads to positive impacts on the participation of individuals. In the intervention, its integration to home routine as a recreational activity is considered to be useful.

\section{Vocational rehabilitation}

Many people diagnosed with autism experience difficulties in finding and sustaining jobs. $50-75 \%$ of this population is estimated to be unemployed [223]. One of the basic problems of individuals with autism in finding jobs is the deficit in social and communication areas, which require advanced support in the workplace [224]. In addition to these personal features, availability and accessibility of services that support employment and existence of social supports are considered as significant environmental factors that affect employment rates [81]. Studies show that individuals with autism may be successful in business life and are considered as important by their employers together with proper vocational interventions [225-227].

Employment opportunities for individuals with autism may be based on two main categories; a) integrated, competition-based employment with supportive employment opportunities and b) separate, non-competitive opportunities including daily therapy, work activity centres and protected businesses. Supportive employment is a system where individuals are supported in the workplace, long term support is given with work coaching system and the support is reduced as the individual becomes more independent. This approach is based on the assumption that all people can work and argues that we should create long-term support mechanism nationally to support this assumption. So the actual question is not whether or not an individual with autism will work but whether or not there is support services required for the individual's success in work performance [228].

Studies show that supportive employment opportunities is the effective way for the participation of individuals with autism in work life [229, 230]. Supportive employment programs have a team consisting of different professions and who work together for common goals in the evaluation of work process, its referral, work analysis, work skills training and follow up of the working individual. This team includes occupational rehabilitation consultant, work coach, occupational therapist, physiotherapist, speech therapist, special trainer, psychologist, individual himself/herself, individual's family and other profession members who may contribute in employment process. Occupational therapists have different roles in assessment, recruitment and training, work development and supportive employment process stages of employment process of individuals with autism. During assessment stage occupational 
therapists assess sensory and motor skills, professional interests, communication and transportation, daily living activities, cognitive, social and community skills, emergency response and safety in workplace and self-assessment skills. During recruitment and training stage occupational therapist work on training and adaptations about work task and settings, identification and training on auxiliary equipment and technology, training on or compensation of basic cognitive skills like attention, visual perception etc., training of work coaches and supporters on use of auxiliary technologies. During work development stage occupational therapist work for increasing environmental support and reducing barriers, doing work analysis, adjusting improvement of conformity between skills of the individual and expectations of the employer and work development in line with interests and skills of individual. In the supportive employment process stage occupational therapist interested in training of work coaches, training on complex cognitive skills such as problem solving, time management, advocating rights of the individual against the employer and other colleagues and cooperation with interdisciplinary team [231].

\subsection{Assessment}

Vocational assessment starts with interview, self-report and behavioural observation. Occupational profile is defined for the occupation and occupational performance analysis is made. It's important to assess strengths, interests and needs of the individual as well as environmental supports and barriers during the interviews [233]. Observation of the individual during occupational performance would provide important information for occupational performance analysis. Other assessments specific to occupational therapy may include sensory-motor skills, socialization skills, cognitive skills and participation in activities of daily living. The Vocational Index, The Autism Work Skills Questionnaire (AWSQ), Vineland Adaptive Behavioural Scale, Adult/Adolescent Sensory Profile, Waisman Activities of Daily Living Scale are examples for standardized assessments that can be used [80, 83, 234-236].

\subsection{Intervention}

Occupational therapists can train the person about skills required for occupation and train his/her natural supports, such as co-workers, supervisors, or family members in the use of adaptive equipment or techniques, environmental adaptations, sensory needs of the person, and compensatory strategies to help the person perform job tasks. Also teaching and compensating for complex cognitive skills such as problem solving, time management, and sequencing to higher functioning persons with autism is within the scope of occupational therapy [232].

Wilczynski, Trammell and Clarke describes forms of technology that can help individuals with autism acquire and maintain employment. According study assistive technology like computer-based systems, personal computers, video recorders, tablets, iPods, iPads, and other devices; video based instruction like video self-modeling, and video games to teach social interaction, covert audio coaching like video modeling instruction initially and follows with audio prompting and alternative support includes personal digital assistants, smartphones, 
and other mobile devices that can be used for auditory and visual reminders, time management, organizational skills, and daily living tasks can enhance the natural support available for individuals with autism in the workplace [237]. Occupational therapists can compensate sensory needs through sensory stimulation or inhibition using techniques such as fidget toys, chewing gum, music, weighted clothing, lighting changes, and increases or decreases in environmental stimuli in workplaces. These changes in the sensory environment may lead to improvement in motor processes, which enable the person to be more productive on the job site [232].

\section{Conclusion}

This chapter provides a brief overview of the wide variety of occupational therapy intervention approaches for individuals with autism. Individuals with autism demonstrate complex behaviours that reguire the integration of different approaches and methods. Occupational therapy interventions varies according to the needs of the individuals with autism. The overall goal of occupational therapy is to help the individual with autism improve quality of life and to enable individuals to participate in everyday occupations. Sensory integration therapy are often used in conjunction with holistic and client centered occupational therapy treatment plan. This practice area is of great importance to the field of occupational therapy in children with autism. Different approaches can assist an individual with autism in a variety of life roles and tasks if it is incorporated into that individual's life in appropriate way. Using effective strategies and technics in occupational therapy intervention program provide opportunities to develop wide range of skills in individuals with autism.

\section{Acknowledgements}

The authors would like to thank Deniz Biyıklı, English language translator, for help in translating and reducting the chapter.

\section{Author details}

Gonca Bumin*, Meral Huri, Sinem Salar and Hulya Kayihan

*Address all correspondence to: gbumin@hacettepe.edu.tr

Department of Occupational Therapy, Faculty of Health Sciences, Hacettepe University, Ankara, Turkey 


\section{References}

[1] American Psychiatric Association (APA). Diagnostic and statistical manual of mental disorders, 4th edn. Washington, DC; 1994.

[2] Kuhaneck MH, Glennon TJ. An Introduction to Autism and the Pervasive Developmental Disorders. In: Kuhaneck MH. (eds) Autism, A Comprehensive Occupational Therapy Approach. USA, The American Occupational Therapy Association; 2001. p1-22.

[3] Baranek GT, David FJ, Poe MD, Stone WL, Watson LR. Sensory Experiences Questionnaire: discriminating sensory features in young children with autism, developmental delays, and typical development. J Child Psychol and Psychiatry 2006;47:591-601.

[4] Baranek GT. Autism during infancy: a retrospective video analysis of sensory-motor and social behaviors at 9-12 months of age. J Autism Dev Disord 1999;29:213-24.

[5] Mailloux Z. Sensory Integrative Principles in Intervention with Children with Autistic Disorder. In: Roley SS, Blanche EI, Schaaf RC. (eds).Understanding the Nature of Sensory Integration with diverse Population; 2001. p365-384.

[6] Kohen-Raz R, Volkmar FR, Cohen DJ. Postural control in children with autism. J Autism Dev Disord 1992;22: 419-32

[7] Molloy CA, Dietrich KN, Bhattacharya A. Postural stability in children with autism spectrum disorder. J Autism Dev Disord 2003;33: 643-52.

[8] Jansiewicz EM, Goldberg MC, Newschaffer CJ, Denckla MB, Landa R, Mostofsky SH. Motor signs distinguish children with high functioning autism and Asperger's syndrome from controls. J Autism Dev Disord 2006;36: 613-21.

[9] Martin SV, Martin N, Vernazze A, Lepellec MA, Rufo M, Massion J, Assaiante C. Goal directed locomotion and balance control in autistic children. J Autism Dev Disord 2005;35: 91-102.

[10] Miyahara M, Tsujiii M, Hori M, Nakanishi K, Kageyama H, Sugiyama T. Brief report: motor incoordination in children with Asperger syndrome and learning disabilities. J Autism Dev Disord 1997;27: 595-603.

[11] American Psychiatric Association (APA). Diagnostic and statistical manual of mental disorders (5th ed.). Arlington, VA: American Psychiatric Publishing; 2013.

[12] Smith JS, Weaver LL, Fristad MA. A systematic review of sensory processing interventions for children with autism spectrum disorders. Autism 2014; 1-16

[13] Ayres AJ. Sensory integration and learning disorders. Los Angeles, CA: Western Psychological Services; 1972. 
[14] Watling R, Deitz J, Kanny EM, Mc Laughlin JF. Current practice of occupational therapy for children with autism. Am J Occup Ther 1999;53: 498-505

[15] Schaaf RC, Miller LJ. Occupational Therapy Using a Sensory Integrative Approach for Children with Developmental Disabilities. Mental Retardation and Developmental Disabilities 2005;11: 143-148.

[16] Kimball JG. Sensory Integration Frame of Reference: Theoretical Base Function/ Dysfunction Continua, and Guide to Evaluation. In: Kramer P, Hinojosa J. (eds). Frames of Reference of Pediatric Occupational Therapy; 1999. p119-159

[17] Spitzer S, Roley SS. Sensory Integration Revisited. In : Roley SS, Blanche EI, Schaaf RC. (eds) Understanding the Nature of Sensory Integration with Diverse Population; 2001. p365-384.

[18] Ayres AJ. Sensory Integration and the Child. Western Psychological Services; 2005.

[19] Scheerer CR. Sensorimotor groups. Activities for School and Home, Therapy Skill Builders; 1997.

[20] Blanche EI, Schaaf RC. Proprioception: A Cornerstone of Sensory Integrative Intervention. In: Roley SS, Blanche EI, Shaaf RC(eds). Understanding the nature of sensory integration with diverse population; 2001. p109-124.

[21] Ornitz EM, The modulation of sensory input and motor output in autistic children. Journal of Autism and Childhood Schizophrenia 1974;4: 197-215.

[22] Parham D, Mailloux Z. Sensory Integration. In: Case Smith J. (ed) Occupational Therapy for Children, Elsevier Mosby; 2005. p356-409.

[23] Schaaf RC, Roley SS. Sensational Ways to Play. In: Schaaf RC, Roley SS (eds) Sensory integration: Applying Clinical Reasoning to Practice with Diverse Populations. Pro.ed; 2006. p195-242.

[24] American Occupational Therapy Association. Occupational Therapy Practice framework: Domain and Process. American Journal of Occupational Therapy 2002; 56: 609-639.

[25] Edwards H. Assessment procedures. In: Wilson BE. (ed) Occupational Therapy for Children with special needs. Whurr Publishers; 2002. p6-31.

[26] Ayres AJ. Sensory Integration and Praxis Tests. Los Angeles: Western Psychological Services; 1989.

[27] Ayres AJ. Southern California Sensory Integration Tests Manual; 1980.

[28] Ayres AJ. Southern California Postrotary Nystagmus Test, Los Angeles: Western Psychological Services; 1975.

[29] Dunn W. The Sensory Profile manual. The Psychological Corporation, San Antonio; 1999. 
[30] Johnson-Ecker CL, Parham LD.The evaluation of sensory processing: a validity study using contrasting groups. Am J Occup Ther 2000;54(5):494-503.

[31] Beery KE. Developmental Test of Visual Motor Integration, 3rd ed. Cleveland, Modern Curriculum Press; 1989.

[32] Colarusso RP, Hammill DD. Motor-Free Visual Perception Test (3rd edition). Novato, CA: Academic Therapy Publications; 2003.

[33] Gardner MF. Test of Visual Perceptual Skills (Non motor) Burlingame: Psychological and Educational Publications; 1988.

[34] Wilson BN, Pollock N, Kaplan BJ, Law M, Frais P. Reliability and construct validity of the clinical observations of motor and postural skills. Am J Occup Ther 1992; 46(9): 775-83.

[35] Mailloux Z, May Benson TA, Summers CA, Miller LJ, Brett Green B, Burke JP. Goal Attainment scaling as a measure of meaningful outcomes for children with sensory integration disorders. Am J Occup Ther 2007; 61(2): 254-9.

[36] Parham DL, Cohn ES, Spitzer S, Koomar JA, Miller LJ, Burke JP et al. Fidelity in sensory ntegration intervention research. Am J Occup Ther 2007; 61: 216-227.

[37] Parham D, Roley SS, May-Benson TA, Koomar J, Brett-Green B, Burke JP, Cohn ES, et al. Development of a fidelity measure for research on the effectiveness of the Ayres Sensory Integration Intervention. Am J Occup Ther 2011; 65(2): 133-42.

[38] Scheerer CR. Sensorimotor Groups. Activities for School and Home. Therapy Skill Builders; 1997.

[39] May Benson TA, Koomar JA. Systematic Review of the research evidence examining the effectiveness of interventions using a sensory integrative approach for children. Am J Occup Ther 2010;64(3):403-14.

[40] Schaaf RC, Hunt J, Benevides T. Occupational therapy using sensory integration to improve participation of a child with autism: a case report. Am J Occup Ther 2012; 66(5): 547-55.

[41] Schaaf RC, Benevides TW, Kelly D, Mailloux-Maggio Z. Occupational therapy and sensory integration for children with autism: a feasibility, safety, acceptability and fidelity study. Autism 2012;16(3): 321-7.

[42] Case-Smith J, Bryan T. The effects of occupational therapy with sensory integration emphasis on preschool-age children with autism. Am J Occup Ther 1999;53: 489-497.

[43] Pfeiffer BA, Koenig K, Kinnealey M, Sheppard M, Henderson L. Effectiveness of Sensory Integration Interventions in Children With Autism Spectrum Disorders: A Pilot Study. Am J Occup Ther 2011;65(1): 76-85. 
[44] Smith SA, Press B, Koenig KP, Kinnealey M. Effects of sensory integration intervention on selfstimulating and self-injurious behaviors. Am J Occup Ther 2005;59: 418425 .

[45] Baranek G. Efficacy of sensory and motor interventions for children with autism. Journal of Autism and Developmental Disorders 2002;32(5): 397-422.

[46] Fazlioglu Y, Baran G. A sensory integration therapy program on sensory problems for children with autism. Perceptual and Motor Skills 2008;106: 115-422.

[47] Cox AL, Gast DL, Luscre D, et al. The effects of weighted vest on appropriate in-seat behaviors of elementary-age students with autism and severe to profound intellectual disabilities. Focus on Autism and Other Developmental Disabilities 2009; 24: 1726.

[48] Bagatell N, Mirigliani G, Patterson C, et al. Effectiveness of therapy ball chairs on classroom participation in children with autism spectrum disorders. Am J Occup Ther 2010;64: 895-903.

[49] Watling RL, Dietz J. Immediate effect of Ayres' sensory integration-based occupational therapy intervention on children with autism spectrum disorders. Am J Occup Ther 2007; 61: 574-583.

[50] Devlin S, Healy O, Leader G, Hughes BM. Comparison of behavioural intervention and sensory-integration therapy in the treatment of challenging behavior. J Autism Dev Disorders 2011;41: 1303-1320.

[51] Davis TN, Durand S, Chan JM. The effects of a brushing procedure on stereotypical behavior. Research in Autism Spectrum Disorders 2011;5: 1053-1058.

[52] Bettison S. Abnormal responses to sound and the long-term effects of a new treatment program. Sydney, Australia: Autism Research Institute; 1994.

[53] Dahlgren SO, Gillberg C. Symptoms in the first two years of life: A preliminary population study of infantile autism. European Archives of Psychology and Neurological Sciences 1989;238: 169-174.

[54] Rimland B, Edelson SM. Brief Report: A Pilot study of Auditory Integration Training in Autism. Journal of Autism and Developmental Disorders 1995;25(1): 61-70.

[55] Sinha Y, Silove N, Hayen A, Williams K. Auditory integration training and other sound therapies for autism spectrum disorders (ASD). Cochrane Database of Systematic Reviews 2011;12: 46.

[56] Dawson G and Watling R. Interventions to Facilitate Auditory, Visual, and Motor Integration in Autism: A Review of the Evidence. Journal of Autism and Developmental Disorders 2000;30(5): 415-421.

[57] Rimland B, Edelson SM. The effects of auditory integration training in autism. American Journal of Speech-Language Pathology 1994;3(2): 16-24. 
[58] Highfill M, Cimorelli J. An objective measure of AIT efficiency: PET imaging. Advance for Speech -Language pathologist and Audiologists 1995;5(25): 5.

[59] Gerritsen J. The effect of Tomatis Therapy on Children with Autism. International Journal of Listening 2010; 24(1).

[60] Brockett SS, Shirley L, Kimball NK, Giencke J. Berard auditory integration training: behavior changes related to sensory modulation. Autism Insights 2014; 26: 1-10.

[61] Al-Ayadhi, Laila Y. Majeed Al-Drees, Abdul Al-Arfaj, Ahmed M. Effectiveness of Auditory Integration Therapy in Autism Spectrum Disorders-Prospective Study. Autism Insights 2013; 5.

[62] Bettison S. The long-term effects of auditory training on children with autism. Journal of Autism and Developmental Disorders 1996; 26: 361-374.

[63] Zollweg W, Vance V, Palm D. The efficacy of auditory integration training: A double blind study. American Journal of Audiology 1997;6: 39-47.

[64] Mudford O, Cross B, Breen S, Cullen C. Auditory integration training: No behavioural benefits detected. American Journal on Mental Retardation 2000; 105:118-129.

[65] American Occupational Therapy Association (AOTA). Occupational therapy practice framework: Domain and process (2nd ed.). American Journal of Occupational Therapy 2008; 62: 625-683.

[66] LeVesser P. Berg C. Participation pattern in preschool children with autism spectrum disorder. OTJR: Occupation, Participation and Health 2011;31: 33-39. http:// dx.doi.org/10.3928/15394492-20100823-01

[67] Rodger S, Umaibalan V. The routines and rituals of families of typically developing children compared with families of children with autism spectrum disorder: An exploratory study. British Journal of Occupational Therapy 2011;74: 20-26. http:// dx.doi.org/10.4276/030802211X12947686093567

[68] Gillham JE, Carter AS, Volkmar FR, et al. Toward a developmental operational definition of autism. Journal of Autism and Developmental Disorders 2000;30(4): 269-278.

[69] Kenworthy L, Black DO, Harrison B et al. Are executive control functions related to autism symptoms in high-functioning children? Child Neuropsychology 2009;15(5): 425-440.

[70] Liss M, Harel B, Fein D, et al. Predictors and correlates of adaptive functioning in children with developmental disorders. Journal of Autism and Developmental Disorders 2001;31(2): 219-230.

[71] Clark GF, Kuhaneck HM, Watling R. Evaluation of the Child With an Autism Spectrum Disorder. In: Kuhaneck HM. (eds) Autism, A Comprehensive Occupational 
Therapy Approach ( $2^{\text {nd }}$ ed). USA, The American Occupational Therapy Association; 2001. p1-22.

[72] Ben-Sasson A, Hen L, Fluss R, Cermak SA, Engel-Yeger B, Gal E. A meta-analysis of sensory modulation symptoms in individuals with autism spectrum disorders. Journal of autism and developmental disorders 2009;39(1): 1-11.

[73] Kientz MA, Dunn WA. Comparison of the performance of children with and without autism on the Sensory Profile. American Journal of Occupational Therapy 1997;51: 530-537

[74] LeCouteur A, Rutter M, Lord C, Rios P, Robertson S, Holdgrafer M, et al. Autism Diagnostic Interview: A standardized investigator-based instrument. Journal of Autism and Developmental Disorders 1989;19: 363-387.

[75] Volkmar FR, Cohen DJ, Paul R. An evaluation of DSM-III criteria for infantile autism. Journal of the American Academy of Child Psychiatry 1986;25: 190-197.

[76] Watling RL, Deitz J, White O. Comparison of Sensory Profile scores of young children with and without autism spectrum disorders. American Journal of Occupational Therapy 2001;55: 416-423.

[77] Koenig K, Rudney S. Performance challenges for children and adolescents with difficulty processing and integrating sensory information: A systematic review. American Journal of Occupational Therapy 2010;64(3): 430-442. doi:10.5014/ajot.2010.09073

[78] Shepherd J. Activities of Daily Living and Adaptations for Indipendent Living. In: Case Smith J. (ed) Occupational Therapy for Children, Elsevier Mosby; 2005. p356-409.

[79] WeeFIM System. WeeFIM system clinical guide, version 5.01. Buffalo, NY: NY University at Buffalo;1999.

[80] Maenner MJ, Smith LE, Hong J, Makuch R, Greenberg JS, Mailick MR. Evaluation of an activities of daily living scale for adolescents and adults with developmental disabilities. Disability and Health Journal 2013;6: 8-17. doi:10.1016/j.dhjo.2012.08.005

[81] Taylor JL, Mailick MR. A longitudinal examination of 10-year change in vocational and educational activities for adults with autism spectrum disorders. Developmental psychology 2014;50(3): 699.

[82] Haley SM. Pediatric Evaluation of Disability Inventory (PEDI): Development, standardization and administration manual. PEDI Resarch Group;1992.

[83] Sparrow SS, Balla DA, Cicchetti DV. Vineland adaptive behavior scales: Interview edition, survey form manual. Circle Pines, MN: American Guidance Service; 1984.

[84] Pan AW, Fisher AG. The Assessment of Motor and Process Skills of persons with psychiatric disorders. American Journal of Occupational Therapy 1994;48(9): 775-780. 
[85] Law M, Baptiste S, Carswell A, McColl M, Polatajko H, Pollock N. Canadian occupational performance measure manual (3rd ed.). Ottawa, Ontario, Canada: Canadian Association of Occupational Therapists; 1998.

[86] Watling R. Behavioral and educational intervention approaches for the child with an autism spectrum disorder. In: Kuhaneck HM. (eds) Autism, A Comprehensive Occupational Therapy Approach ( $2^{\text {nd }}$ ed). USA, The American Occupational Therapy Association; 2001.

[87] Kazdin A. Behavior modification in applied settings (5th ed.). Pacific Grove, CA: Brook/Cole; 1994.

[88] Giles GM, Ridley JE, Dill A, Frye S. A consecutive series of adults with brain injury treated with a washing and dressing retraining program. American Journal of Occupational Therapy 1997;51(4): 256-266.

[89] Schopler E, Mesibov GB, Hearsey K. Structured teaching in the TEACCH system. In Schopler E, Mesibov GB (eds.), Learning and cognition in autism. New York: Plenum;1995. p243-267).

[90] Simpson RL, Myles BS, Ganz JB. Efficacious interventions and treatments for learners with autism spectrum disorders. In Simpson RL, Myles BS. (Eds.), Educating children and youth with autism: Strategies for effective practice (2nd ed). Austin, TX: Pro-Ed, Inc.; 2008. p477-512

[91] Bryan LC, Gast DL. Teaching on-task and on-schedule behaviors to high-functioning children with autism via Picture activity schedules. Journal of Autism \& Developmental Disorders 2000;30: 553-567.

[92] Van Laarhoven T, Kraus E, Karpman K, Nizzi R, Valentino J. A comparison of picture and video prompts to teach daily living skills to individuals with autism. Focus on Autism and Other Developmental Disabilities 2010;25(4): 195-208.

[93] Goldsmith TR, LeBlanc LA. Use of Technology in Interventions for Children with Autism. Journal of Early and Intensive Behavior Intervention 2004;1(2): 166-178.

[94] Shipley-Benamou R, Lutzker JR, Taubman M. Teaching daily living skills to children with autism through instructional video modeling. Journal of Positive Behavior Interventions 2002;4(3):166-177.

[95] Kuo R, Chand M, Lyu CW, Heh JS. A Pilot Study of The Situated Game For Autistic Children Learning Activities of Daily Living. Research \& Practice in Technology Enhanced Learning 2013;8(2).

[96] Bundy AC. Play theory and sensory integration. Sensory integration: Theory and practice;1991. p46-68. 
[97] Pierce-Jordan S, Lifter K. Interaction of social and play behaviors in preschoolers with and without pervasive developmental disorder. Topics in Early Childhood Special Education 2005;25(1): 34-47.

[98] Boutot EA, Guenther T, Crozier S. Let's Play: Teaching Play Skills to Young Children with Autism. Education and Training in Developmental Disabilities 2005;40(3): 285-292.

[99] Parham LD, Fazio LS (Eds.). Play in occupational therapy for children. St. Louis, MO: Mosby;1997.

[100] Case-Smith J, O'Brien JC. Occupational therapy for children. Elsevier Health Sciences; 2013.

[101] Rodger S, Ziviani J. Play-based occupational therapy. International Journal of Disability, Development and Education 1999;46(3): 337-365.

[102] Bundy AC. Assessment of play and leisure: Delineation of the problem. American Journal of Occupational Therapy 1993;47(3): 217-222.

[103] Bundy AC. Play and playfulness: What to look for. Play in occupational therapy for children;1997. p52-66.

[104] Ayres AJ. Learning disabilities and the vestibular system. Journal of Learning Disabilities 1978;11(1): 30-41.

[105] Ayres AJ, Tickle LS. Hyper-responsivity to touch and vestibular stimuli as a predictor of positive response to sensory integration procedures by autistic children. The American journal of occupational therapy: official publication of the American Occupational Therapy Association 1980;34(6): 375-381.

[106] Roley SS, Mailloux Z, Kuhaneck MH, Glennon T. Understanding Ayres' Sensory Integration; 2007.

[107] Cermak S. Developmental dyspraxia. Advances in psychology 1985;23: 225-248.

[108] Cermak S. Somatodyspraxia. In Fisher A, Murray E, Bundy A (Eds). Sensory integration: Theory and practice 1991; p137-165. Philadelphia: EA. Davis.

[109] Iarocci G, McDonald J. Sensory integration and the perceptual experience of persons with autism. Journal of autism and developmental disorders 2006;36(1): 77-90.

[110] Liao ST, Hwang YS, Chen YJ, Lee P., Chen SJ, Lin LY. Home-based DIR/Floortime ${ }^{\mathrm{TM}}$ Intervention Program for Preschool Children with Autism Spectrum Disorders: Preliminary Findings. Physical \& occupational therapy in pediatrics, 2014.

[111] Case-Smith J, Arbesman M. Evidence-based review of interventions for autism used in or of relevance to occupational therapy. American Journal of Occupational Therapy 2008;62(4): 416-429. 
[112] Hébert ML, Kehayia E, Prelock P, Wood-Dauphinee S, Snider L. Does occupational therapy play a role for communication in children with autism spectrum disorders? Int J Speech Lang Pathol 2014; (0): 1-9.

[113] Pellegrini AD, Dupuis D, Smith PK. Play in evolution and development. Developmental Review 2007;27(2): 261-276.

[114] Bundy AC, Nelson L, Metzger M, Bingaman K. Validity and reliability of a test of playfulness. Occupational Therapy Journal of Research 2001;21(4): 276-292.

[115] Knox S. Development and current use of the Knox Preschool Play Scale. Play in occupational therapy for children 1997; p35-51.

[116] Stagnitti K, Unsworth C. The importance of pretend play in child development: An occupational therapy perspective. The British Journal of Occupational Therapy 2000;63(3): 121-127.

[117] Stagnitti K. Understanding play: The implications for play assessment. Australian Occupational Therapy Journal 2004;51(1): 3-12.

[118] Taylor K, Menarchek-Fetkovich M, Day C. The play history interview. Play Diagnosis and Assessment 2000; p114-139.

[119] Linder TW. Transdisciplinary play-based assessment: A functional approach to working with young children (Rev. ed.). Baltimore: Paul H. H. Brookes; 1993.

[120] O'Brien J, Coker P, Lynn R, Suppinger R, Pearigen T, Rabon S, Ward AT. The impact of occupational therapy on a child's playfulness. Occupational Therapy in Health Care 2000;12(2-3): 39-51.

[121] Schneider E, Rosenblum, S. Development, reliability, and validity of the My Child's Play (MCP) questionnaire. Am J Occup Ther 2014; 68(3): 277-85.

[122] Skaines N, Rodger S, Bundy A. Playfulness in children with autistic disorder and their typically developing peers. The British Journal of Occupational Therapy 2006;69(11): 505-512.

[123] Yack E, Sutton S, Aquilla P. Building bridges through sensory integration: Therapy for children with autism and other pervasive developmental disorders. Future Horizons; 2003.

[124] Anzalone ME, Williamson GG. Sensory processing and motor performance in autism spectrum disorders. Autism Spectrum Disorders: A transactional Developmental Perspective 2000;9: 143-166.

[125] Pajareya K, Nopmaneejumruslers K. A pilot randomized controlled trial of DIR/ Floortime ${ }^{\mathrm{TM}}$ parent training intervention for pre-school children with autistic spectrum disorders. Autism 2011;15(5): 563-577. 
[126] Solomon R, Necheles J, Ferch C, Bruckman D. Pilot study of a parent training program for young children with autism: The PLAY Project home consultation program. Autism 2007;11(3): 205-224.

[127] Strickland D. Virtual reality for the treatment of autism. Studies in Health Technology and Informatics, 1997; p81-86.

[128] Law M, Cooper B, Strong S, Stewart D, Rigby P, Letts L. The person-environmentoccupation model: A transactive approach to occupational performance. Canadian Journal of Occupational Therapy 1996;63(1): 9-23.

[129] Linder, TW. Transdisciplinary play-based assessment: A functional approach to working with young children. rev. Paul H Brookes Publishing; 1993.

[130] Ingersoll B, Schreibman L, Stahmer A. Brief report: Differential treatment outcomes for children with autistic spectrum disorder based on level of peer social avoidance. Journal of Autism and Developmental Disorders 2001;31(3): 343-349.

[131] Baron-Cohen S, Leslie AM, Frith U. Does the autistic child have a "theory of mind?.Cognition 1985;21(1): 37-46.

[132] Tager-Flusberg H, Paul R, Lord C. Language and communication in autism. Handbook of autism and pervasive developmental disorders 2005;1:335-364.

[133] Ozonoff S. Executive functions in autism. In Learning and cognition in autism. Springer US; 1995. p199-219.

[134] Pennington BF, Ozonoff S. Executive functions and developmental psychopathology. Journal of child psychology and psychiatry 1996;37(1): 51-87.

[135] Happé F, Briskman J, \& Frith U. Exploring the cognitive phenotype of autism: Weak "central coherence" in parents and siblings of children with autism: I. Experimental tests. Journal of child psychology and psychiatry 2001;42(3): 299-307

[136] Kasari C, Locke J, Gulsrud A, Rotheram-Fuller E. Social networks and friendships at school: Comparing children with and without ASD.Journal of autism and developmental disorders 2011;41(5): 533-544.

[137] Leaf JB, Taubman M., Bloomfield S., Palos-Rafuse L., Leaf R., Mc Eachin J. and Oppenhaim ML. Increasing social skills and pro-social behavior for three children diagnosed with autism through the use of a reaching package. Research in Autism Spectrum Disorders 2009;3:275-289. Journal homepage: http://ees.elseiver.com/ RASD/default.asp.

[138] Matson JL, Matson ML. and Rivet TT. Social-skills treatments for children with autism spectrum disorders. An overview. Behavior Modification 2007;31(5): 682-707.

[139] Attwood T. Strategies for improving the social integration of children with Asperger syndrome, Autism: The International Journal of Research and Practice 2000;4(1): 85-100. 
[140] Baker JE. Social skills training for children and adolescents with Asperger Syndrome and Social Communication Problems. Shawnee mission, KS: Autism Asperger Publishing Company; 2003.

[141] Myles B. Overview of Asperger syndrome. In Jed E. Baker (Eds.) Social skills training KS: Autism Asperger Publishing Company; 2003. p9-17.

[142] Howlin P, Baron-Cohen S, Hadwin J. Teaching children with autism to mind-read: a practical guide, Chichester, John Willey \& Sons; 2003.

[143] Howlin P, Yates P. The Potential Effectiveness of Social Skills Groups for Adults with Autism. Autism, The International Journal of Research and Practice 1999;3(3): 299-307.

[144] McGinnis E, Goldstein AP. Skillstreaming in early childhood: New strategies and perspectives for teaching prosocial skills. Research Press; 2003.

[145] Wieder S, Greenspan SI. Climbing the symbolic ladder in the DIR model through floor time/interactive play. Autism 2003;7(4): 425-435.

[146] Rao PA, Beidel DC, Murray MJ. Social skills interventions for children with Asperger's syndrome or high-functioning autism: A review and recommendations. Journal of autism and developmental disorders 2008;38(2): 353-361.

[147] Rogers SJ, Vismara LA. Evidence-based comprehensive treatments for early autism. Journal of Clinical Child \& Adolescent Psychology 2008;37(1): 8-38.

[148] Rodgers J. Visual perception and asperger syndrome: Central coherence deficit or hierarchization deficit? The International Journal of Research and Practice 2000;4: 321-329.

[149] Reynhout G, Carter M. Social Stories ${ }^{\mathrm{TM}}$ for children with disabilities.Journal of autism and developmental disorders 2006;36(4): 445-469.

[150] DiSalvo CA, Oswald DP. Peer-mediated interventions to increase the social interaction of children with autism consideration of peer expectancies. Focus on autism and other developmental disabilities 2002;17(4): 198-207.

[151] Barry TD, Klinger LG, Lee JM, Palardy N, Gilmore T, Bodin SD. Examining the effectiveness of an outpatient clinic-based social skills group for high-functioning children with autism. Journal of autism and developmental disorders 2003;33(6): 685-701.

[152] White SW, Keonig K, Scahill L. Social skills development in children with autism spectrum disorders: A review of the intervention research.Journal of autism and developmental disorders 2007;37(10): 1858-1868.

[153] Cartledge G. Teaching social skills to children: Innovative approaches(Vol. 89). Allyn \& Bacon; 1986. 
[154] Gresham FM, Elliott SN. Social skills rating system: Manual. American Guidance Service; 1990.

[155] Foster L, Dunn W, Lawson LM. Coaching mothers of children with autism: a qualitative study for occupational therapy practice. Physical \& occupational therapy in pediatrics 2013;33(2): 253-263.

[156] Gray C. The orginal social story book. Arlington, VA: Future Horizons; 1986.

[157] Myles BS. Interventions in School, Home, and Community for Individuals with Autism Spectrum Disorders. In Interventions for Autism Spectrum Disorders. Springer New York; 2013. p303-323.

[158] Volkmar F, Siegel M, Woodbury-Smith M, King B, McCracken J, State M. Practice parameter for the assessment and treatment of children and adolescents with autism spectrum disorder. Journal of the American Academy of Child and Adolescent Psychiatry 2014;53(2): 237-257.

[159] Bruce MA, Borg B. Psychosocial frames of reference: Core for occupation-based practice. Slack Incorporated; 2002.

[160] Association for Behavioral and Cognitive Therapies Evidenced-based mental health treatments for children and adolescence; 2010. Available from http://www.abct.org/ sccap/?m=sPro\&fa=pro_ESToptions\#sec13 (accessed 25 July 2014).

[161] Ikiugu MN. Instrumentalism in occupational therapy: An argument for a pragmatic conceptual model of practice. International Journal of Psychosocial Rehabilitation 2004;8: 109-117.

[162] Kielhofner G. Conceptual foundations of occupational therapy practice. FA Davis; 2009.

[163] Haglund L, Ekbladh E, Thorell LH, Hallberg IR. Practice models in Swedish psychiatric occupational therapy. Scandinavian Journal of Occupational Therapy 2000;7(3): 107-113.

[164] Morley S, Eccleston C, Williams A. Systematic review and meta-analysis of randomized controlled trials of cognitive behaviour therapy and behaviour therapy for chronic pain in adults, excluding headache. Pain 1999;80(1): 1-13.

[165] Graff MJ, Vernooij-Dassen MJ, Thijssen M, Dekker J, Hoefnagels WH, Rikkert MG. Community based occupational therapy for patients with dementia and their care givers: randomised controlled trial. Bmj 2006;333(7580): 1196.

[166] Lang R, Regester A, Lauderdale S, Ashbaugh K, Haring A. Treatment of anxiety in autism spectrum disorders using cognitive behaviour therapy: A systematic review. Developmental Neurorehabilitation 2010;13(1): 53-63.

[167] Buron KD, Curtis M. The incredible 5-point scale. Shawnee Mission; 2003. 
[168] Gagnon E. Power Cards: Using Special Interests To Motivate Children and Youth with Asperger Syndrome and Autism. Autism Asperger Publishing Co.; 2001. PO Box 23173, Shawnee Mission, KS 66283-0173.

[169] Strobel D. Bibliotherapy: An intervention designed for siblings of children with autism. PhD thesis. Northern Illinois University; 2011.

[170] Bellini S, Akullian J. A meta-analysis of video modeling and video self-modeling interventions for children and adolescents with autism spectrum disorders. Exceptional Children 2007;73(3): 264-287.

[171] Myles BS, Simpson RL. Understanding the hidden curriculum: An essential social skills for children and youth with Asperger Syndrome. Intervention in School and Clinic 2001;36(5): 279-286.

[172] Myles BS, Trautman ML, Schelvan RL. The hidden curriculum. Practical solutions for understanding unstated rules in social situations. Shawnee Mission, KS: Autism Asperger Publishing Co.; 2004.

[173] Livanis A, Solomon ER, Ingram DH. Guide social stories: Group treatments of adolescents with Asperger's Disorder in the schools. In Handbook of Cognitive-Behavior Group Therapy with Children and Adolescents. Christner RW, Stewart JL, Freeman A (eds.). New York, New York: Routledge Press; 2007.

[174] Winner MG. Thinking about you thinking about me. San Jose, CA: Michelle Garcia Winner; 2002.

[175] Williams MS, Shellenberger S. How does your engine run? A leader's guide to the alert program ${ }^{\circledR}$ for self-regulation. Albuquerque, NM: Therapy Works, Inc.; 1996.

[176] Winner MG. Think social! San Jose, CA: Michelle Garcia Winner; 2005.

[177] Winner MG. Worksheets for teaching social thinking and related skills. San Jose, CA: Think Social Publishing, Inc.; 2005.

[178] Madrigal S, Winner M. Superflex...A superhero social thinking curriculum. San Jose, CA: Think Social Publishing, Inc. ; 2008.

[179] Attwood T. Exploring feelings: Cognitive behavior therapy to manage anger. Arlington, TX: Future Horizons; 2004.

[180] American Occupational Therapy Association. Guidelines for occupational therapy services in school systems. American Occupational Therapy Association, Incorporated; 1989 .

[181] Dunn W. A Comparison of Service Provision Models in School-Based Occupational Therapy Services: A Pilot Study. Occupational Therapy Journal of Research 1990;10(5): 300-20. 
[182] Wehrmann S, Chiu T, Reid D, Sinclair G. Evaluation of occupational therapy schoolbased consultation service for students with fine motor difficulties. Canadian Journal of Occupational Therapy 2006;73(4): 225-235.

[183] Burtner PA, McMain MP, Crowe TK. Survey of occupational therapy practitioners in southwestern schools: Assessments used and preparation of students for schoolbased practice. Physical and Occupational Therapy in Pediatrics 2002;22(1): 25-39.

[184] Case-Smith J. Effectiveness of school-based occupational therapy intervention on handwriting. American Journal of Occupational Therapy 2002;56(1): 17-25.

[185] Law MC, Baum CM, Dunn W (Eds.). Measuring occupational performance: Supporting best practice in occupational therapy. Slack Incorporated; 2005.

[186] Reid D, Chiu T, Sinclair G, Wehrmann S, Naseer Z. Outcomes of an occupational therapy school-based consultation service for students with fine motor difficulties. Canadian Journal of Occupational Therapy 2006;73(4): 215-224.

[187] Benson J, Florence C. A guide for instrument development and validation. American Journal of Occupational Therapy 1982.

[188] Woodward S, Swinth Y. Multisensory approach to handwriting remediation: Perceptions of school-based occupational therapists. American Journal of Occupational Therapy 2002;56(3): 305-312.

[189] Tomchek SD, Dunn W. Sensory processing in children with and without autism: a comparative study using the short sensory profile. American Journal of occupational therapy 2007;61(2): 190-200.

[190] American Occupational Therapy Association. Applying sensory integration framework in educationally related occupational therapy practice. American Journal of Occupational Therapy 2003;57: 652-59.

[191] Beery K, Buktenica NA, Beery N. Beery VMI (5th ed.). La Mesa, CA: Jerome M. Sattler; 2006.

[192] Folio MR, Fewell RR. Peabody Developmental Motor Scales-2nd Edition; 1974.

[193] Bruininks R, Bruininks B. Bruinincks-Osteretsky test of motor proficiency (2nd ed.). Bloomington, MN: AGS; 2006.

[194] American Occupational Therapy Association. Occupational therapy in educational settings under the Individuals with Disabilities Education Act. Bethesda, MD: Author; 2006.

[195] Hinder EA, Ashburner J. Occupation-centred intervention in the school setting. Occupation-centred practice with children: A practical guide for occupational therapists; 2010. p227-247. 
[196] Jackson LL (Ed.). Occupational therapy services for children and youth under IDEA (3rd.ed.). Bethesda, MD: AOTA Press; 2007.

[197] World Health Organization. International Classification of Functioning, Disability and Health. Geneva: Author; 2001.

[198] Larson RW. Toward a psychology of positive youth development. American Psychologist 2000;55(1): 170-183.

[199] King G, Law M, King S, Rosenbaum P, Kertoy MK, Young NL. A conceptual model of the factors affecting the recreation and leisure participation of children with disabilities. Physical and Occupational Therapy in Pediatrics 2003;23(1): 63-90. doi: 10.1080/J006v23n01_05.

[200] Mactavish JB, Schleien SJ. Re-injecting spontaneity and balance in family life: Parents' perspective on recreation in families that include children with developmental disability. Journal of Intellectual Disability Research 2004;48(2): 123-141. doi: 10.1111/j.1365-2788.2004.00502.x.

[201] Passmore A. The occupation of leisure: Three typologies and their influence on mental health in adolescence. OTJR: Occupation, Participation and Health 2003;23(2):7683.

[202] Wilson A, Arnold M, Rowland ST, Burnham S. Promoting recreation and leisure activities for individuals with disabilities: A collaborative effort. Journal of Instructional Psychology 1997;24(1): 76-79.

[203] Coyne P, Fullerton A. Supporting individuals with autism spectrum disorder in recreation.(second ed.) Urbana, IL: Sagamone; 2014.

[204] Pan CY. Effects of water exercise swimming program on aquatic skills and social behaviors in children with autism spectrum disorders. Autism 2010;1: 9-28.

[205] Prupas A, Reid G. Effects of exercise frequency on stereotypic behaviors of children with developmental disorders. Education and Training in Mental Retardation and Developmental Disorders 2001;36: 196-206.

[206] Yılmaz I, Yanardağ M, Birkan B, Bumin G. Effects of swimming training on physical fitness and water orientation in autism, Pediatrics International 2004;46: 624-626.

[207] Bass MM, Duchowny CA, Llabre MM. The effect of therapeutic horseback riding on social functioning in children with autism. Journal of Autism and Developmental Disorders 2009;39: 1261-1267.

[208] Potvin MC, Prelock PA, Snider L. Collaborating to support meaningful participation in recreational activities of children with autism spectrum disorder. Topics in Language Disorders 2008;28: 365-374. 
[209] Hilton CL, Crouch MC, Israel H. Out-of-school participation patterns in children with high-functioning autism spectrum disorders. The American Journal of Occupational Therapy 2008;62: 554-563.

[210] Solish A, Perry A, Minnes P. Participation of children with and without disabilities in social, recreational and leisure activities. Journal of Applied Research in Intellectual Disabilities 2010;23: 226-236. doi:10.1111/j.1468 3148.2009.00525.x.

[211] Lee LC, Harrington RA, Louie BB, Newschaffer CJ. Children with autism: Quality of life and parental concerns. Journal of Autism and Developmental Disorders 2008;38(6): 1147-1160. doi:10.1007/s10803-007-0491-0.

[212] Potvin MC, Snider L, Prelock P, Kehayia E, Wood-Dauphinee S. Recreational participation of children with high functioning autism. Journal of Autism and Developmental Disorders 2013;43(2): 445-457.

[213] Hochhauser M, Engel-Yeger B. Sensory processing abilities and their relation to participation in leisure activities among children with high-functioning autism spectrum disorder (HFASD). Research in Autism Spectrum Disorders 2010;4(4): 746-754.

[214] Orsmond G, Krauss M, Seltzer M. Peer relationships and social and recreational activities among adolescents and adults with autism. Journal of Autism and Developmental Disorders 2004;34: 245-256.

[215] Fox L, Vaughn BJ, Wyatte ML, Dunlap G. “We can't expect other people to understand": Family perspectives on problem behavior. Exceptional Children 2002;68(4): 437-450.

[216] Mandich A, Polatajko H, Miller L, Baum C. Paediatric Activity Card Sort. CAOT Publications ACE, Ottawa; 2004.

[217] King GA, Law M, King S, Hurley P, Rosenbaum P, Hanna S, et al. Children's Assessment of Participation and Enjoyment and Preferences for Activities of Kids. San Antonio, TX: PsychCorp; 2004.

[218] Carter EW, Hughes C. Including high school students with severe disabilities in general education classes: perspectives of general and special educators, paraprofessionals, and administrators. Research \& Practice for Persons with Severe Disabilities 2006;31 (2): 174-185.

[219] Carter EW, Pesko MJ. Social validity of peer interaction intervention strategies in high school classrooms: Effectiveness, feasibility, and actual use. Exceptionality 2008;16: 156-173.

[220] Bauman ML, Kemper TL. Neuroanatomic observation of the brain in autism. In Bauman ML and Kemper TL (Eds.). The neurology of autism. Baltimore: Johns Hopkins University Press; 1994. p119-145.

[221] Courchesne E, Townsend JP, Akshoomoff NA, Yeung-Courhesne R, Press GA, Murakami JW et al. A new finding: Impairment in shifting attention in autistic and cere- 
bellar patients. In: Broman SH and Grafman J. (Eds.). Atypical cognitive deficits in developmental disorder: Implications for brain functions. Hillsdale, NJ: Erlbaum; 1993. p101-137.

[222] Rizzo AA, Kim GJ. "A SWOT analysis of the field of VR rehabilitation and therapy". Presence: Teleoperators and Virtual Environments 2005;14: 119-146.

[223] Wehman P, Lau S, Molinelli A, Brooke V, Thompson K, Moore C, West M. Supported Employment for Young Adults With Autism Spectrum Disorder: Preliminary Data. Research and Practice for Persons with Severe Disabilities 2012;37: 160-169. doi: 10.2511/027494812804153606

[224] Allen KD, Burke RV, Howard MR, Wallace DP, Bowen SL. Use of audio cuing to expand employment opportunities for adolescents with autism spectrum disorders and intellectual disabilities. Journal of autism and developmental disorders 2012;42(11): 2410-2419.

[225] Hagner D. Cooney BF. "I do that for everybody": supervising employees with autism. Focus on Autism and Other Developmental Disabilities 2005;20(2): 91-97.

[226] Hurlbutt K, Chalmbers L. Employment and adults with Asperger syndrome, Focus on Autism and Other Developmental Disabilities 2004;19(4): 215-222.

[227] Kregel J. Why it pays to hire workers with developmental disabilities. Focus on Autism and Other Developmental Disabilities 1999;14(3): 130-132.

[228] Orentlicher ML, Olson LJ. Transition from School to Adult Life for Students with an Autism Spectrum Disorder. In: Kuhaneck MH. (eds) Autism, A Comprehensive Occupational Therapy Approach. USA, The American Occupational Therapy Association; 2004. p359-386.

[229] Hillier H, Campbell K, Mastriana M, Izzo A, Kool-Tucker L, Cherry L, et al. Twoyear evaluation of a vocational support program for adults on the autism spectrum. Career Development for Exceptional Individuals 2007;30(1): 35-47.

[230] Keel JH, Mesibov GB, Woods A. TEACCH-supported employment program. Journal of Autism and Developmental Disorders 1997; 27: 3-9.

[231] Reed CA, Rumrill Jr PD. Supported employment: Principles and practices for interdisciplinary collaboration, Work: A Journal of Prevention, Assessment, and Rehabilitation 1997; 9(3): 237-244.

[232] Capo LC. Autism, employment, and the role of occupational therapy. Work: A Journal of Prevention, Assessment and Rehabilitation 2001;16(3): 201-207.

[233] Pitts DB. Work as Occupation. In: Brown C, Stoffel VC. (Eds.). Occupational Therapy in Mental Health: A Vision for Participation. F.A.Davis Company: Philadelphia; 2011. 
[234] Taylor JL, Seltzer MM. Developing a vocational index for adults with autism spectrum disorders. Journal of Autism and Developmental Disorders 2012; 4: 2669-2679. doi:10.1007/s10803-012-1524-x

[235] Brown C, Dunn W. Adolescent/Adult Sensory Profile. Psychological Corporation, San Antonio, TX; 2002.

[236] Gal E, Meir AB, Katz N. Development and Reliability of the Autism Work Skills Questionnaire (AWSQ). American Journal of Occupational Therapy 2013; 67(1): e1e5.

[237] Wilczynski S, Trammell B, Clarke L. Improving employment outcomes among adolescents and adults on the Autism Spectrum. Psychology in Schools 2013;50(9): 876-887. doi: 10.1002/pits.21718. 
